\title{
Immunotherapy for Prostate Cancer
}

\author{
Nicholas J. Venturini ${ }^{1}$ and Charles G. Drake ${ }^{1,2}$ \\ ${ }^{1}$ Division of Hematology and Oncology, Herbert Irving Comprehensive Cancer Center, \\ Columbia University Medical Center, New York, New York 10032 \\ ${ }^{2}$ Department of Urology, Columbia Medical Center, New York, New York 10032 \\ Correspondence: cgd2139@cumc.columbia.edu
}

\begin{abstract}
Immunotherapy with agents that block immune checkpoints is a mainstay of therapy for several common tumor types; so far, prostate cancer is not among those treated using this method. The observed lack of activity in prostate cancer is not due to a lack of testing; several agents have been evaluated both alone and in combination. Although several combination strategies show some promise, it appears likely that a greater understanding of the prostate cancer tumor microenvironment and baseline immune response will be required to optimize future treatment strategies.
\end{abstract}

$P^{r}$ rostate cancer is the most commonly diagnosed cancer and the second most deadly cancer among American men, accounting for $19 \%$ of new cancer diagnoses and $9 \%$ of cancer deaths (Siegel et al. 2018). As of 2018, it is estimated that one in nine men will be diagnosed with prostate cancer during his lifetime. Patients presenting with localized prostate cancer are treated with surgical resection (radical prostatectomy) or radiation therapy (brachytherapy or external beam radiotherapy) (Sanda et al. 2018). After initial treatment, patients are routinely monitored for rising prostate-specific antigen (PSA) levels in the blood, which indicate biochemical recurrence (BCR) (Paller et al. 2013). Approximately $35 \%$ of prostate cancer patients will experience BCR and require further treatment at some point, generally with androgen deprivation therapy (ADT), using either chemical or surgical castration. Although ADT is initially efficacious, if patients live sufficiently long, they will eventually develop metastatic castration-resistant prostate cancer (mCRPC), a more advanced form of the disease with an estimated survival generally in the 2-3-year range (Scher et al. 2016). Immunotherapy based on the blockade of immune checkpoints plays a role in the treatment of most advanced cancers (Topalian et al. 2015); prostate cancer is currently a notable exception (Drake et al. 2014). Here, we will review the mechanisms of action of immunotherapy and discuss clinical data in prostate cancer. In particular, we will focus on mechanisms by which prostate cancer, particularly advanced prostate cancer, may thwart immune attack. Finally, we will outline future directions for the field, with an emphasis on combination regimens-involving both conventional agents as well as immune/immunotherapy combinations.

Editors: Michael M. Shen and Mark A. Rubin

Additional Perspectives on Prostate Cancer available at www.perspectivesinmedicine.org

Copyright (C) 2019 Cold Spring Harbor Laboratory Press; all rights reserved; doi: 10.1101/cshperspect.a030627

Cite this article as Cold Spring Harb Perspect Med 2019;9:a030627 


\section{THE ADAPTIVE IMMUNE RESPONSE AND CANCER}

The major effector cell in the adaptive immune system is the CD8 (killer) T cell; activated CD8 T cells circulate throughout the body where they are capable of entering nearly any tissue. These cells are specialized for killing; when they encounter their target ligand, they use multiple mechanisms to mediate apoptosis of specific target cells. This killing process is exquisitely selective; specificity is enforced by a requirement for a tight fit between the T-cell receptor (TCR) on a CD8 $\mathrm{T}$ cell and its ligand. Interestingly, the ligand for a TCR is not a single protein; instead, it consists of a molecular complex generated when a peptide is loaded into the groove of a class I major histocompatibility complex (MHC) molecule. T cells thus "survey" tissues, testing cell surfaces for the expression of their cognate ligand in the context of a class I MHC molecule. When an appropriate fit is detected, the $\mathrm{T}$ cell ceases trafficking and pauses, generating a shortterm cell-to-cell interaction known as an immunological synapse. In addition to cytokines like interferon (IFN)- $\gamma$, activated CD8 T cells secrete perforins across that synapse. These pore-forming molecules punch holes in the target cells, generating osmotic disequilibrium. More important, activated CD8 $\mathrm{T}$ cells secrete molecules called "granzymes," which enter the cytoplasm of the target cell and induce apoptosis, or programmed cell death. Activated CD8 T cells can lyse even chemotherapy-resistant tumor cells and are thus a powerful antitumor weapon.

During the course of tumorigenesis, transformed cells express mutated or nonnative proteins, and peptide fragments from those proteins are loaded into the groove of class I MHC molecules. These "foreign" peptides are likely immunogenic, rendering tumor cells that express them susceptible to CD8-medited immune attack. This process is known as "editing." It is thus likely that the tumor masses that become clinically apparent in immunocompetent hosts have already undergone some degree of immune editing (Dunn et al. 2004). The "edited" tumor then reaches a stage of equilibrium with the immune system, during which further outgrowth is blocked by immune mechanisms while the tumor strives to escape and proliferate. Expanding tumors in patients are at the "escape" stage of development, in which they have escaped recognition by both the innate and adaptive immune systems.

\section{PD-1/PD-L1 AND IMMUNE ESCAPE}

One of the key molecular pathways involved in immune escape by tumors is the programmed death-1 (PD-1) pathway (LaFleur et al. 2018). $\mathrm{PD}-1$ is a cell surface marker originally identified from a cDNA library of $\mathrm{T}$ cells undergoing apoptosis (Ishida et al. 1992). For some time, its function was relatively obscure (Agata et al. 1996; Nishimura et al. 1996), until global knockout mice were generated (Nishimura et al. 2001). Those mice showed clear but not overwhelming autoimmune disease. Perhaps more salient was the discovery that the ligand for PD-1, PD-L1 (Dong et al. 1999; Keir et al. 2006), is expressed on tumor cells across a number of histologies, including prostate cancer (Haffner et al. 2018). This discovery led to the unraveling of a molecular system used by inflamed tissues to thwart unwanted T-cell attack-a system effectively hijacked by a number of tumor types.

In this model, specific $\mathrm{T}$ cells enter a tumor or inflamed tissue and encounter their cognate ligands. As a consequence of engagement, the $\mathrm{T}$ cells secrete IFN- $\gamma$, which binds to receptors on epithelial cells. Sensing that it is "under attack," the epithelial cell up-regulates PD-L1 in a Stat-1dependent manner. PD-L1 on the tumor cell binds to PD- 1 on the attacking T cells, effectively paralyzing them and preventing further immune attack. The process by which tumors "adapt" to immune attack has been termed "adaptive immune resistance" (Taube et al. 2012). Although originally described in melanoma samples, adaptive immune resistance has been documented in a number of tumor types, including prostate cancer (Martin et al. 2015). One of the implications of adaptive immune resistance is that blocking the PD-1/PD-L1 interaction could lead to $\mathrm{T}$ cells reacquiring effector function-with subsequent tumor lysis and regression. This is indeed the case, as objective 
antitumor responses were observed in the very first trial of anti-PD-1 (Topalian et al. 2012) and PD-1 or PD-L1 blocking antibodies are now U.S. Food and Drug Administration (FDA)-approved in about nine tumor types (LaFleur et al. 2018).
This process is outlined in Figure 1. The process begins when an antigen presented in the context of MHC class I on a tumor cell is recognized by a TCR on a T cell (shown in Fig. 1A). This recognition leads to T-cell activation and subsequent up-regulation of PD-1 expres-
A

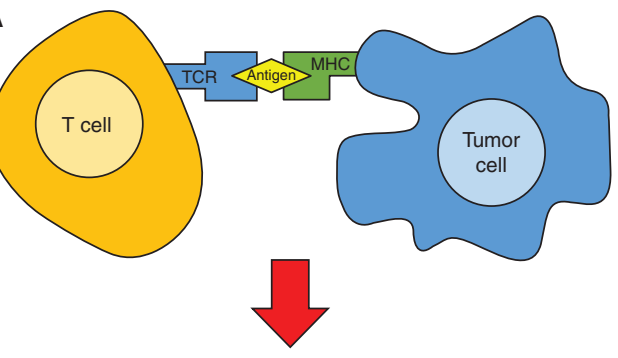

B

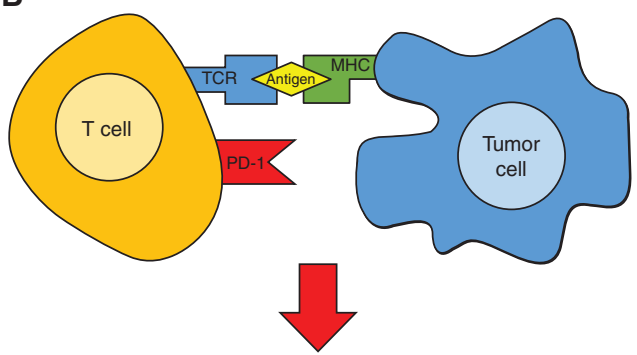

C
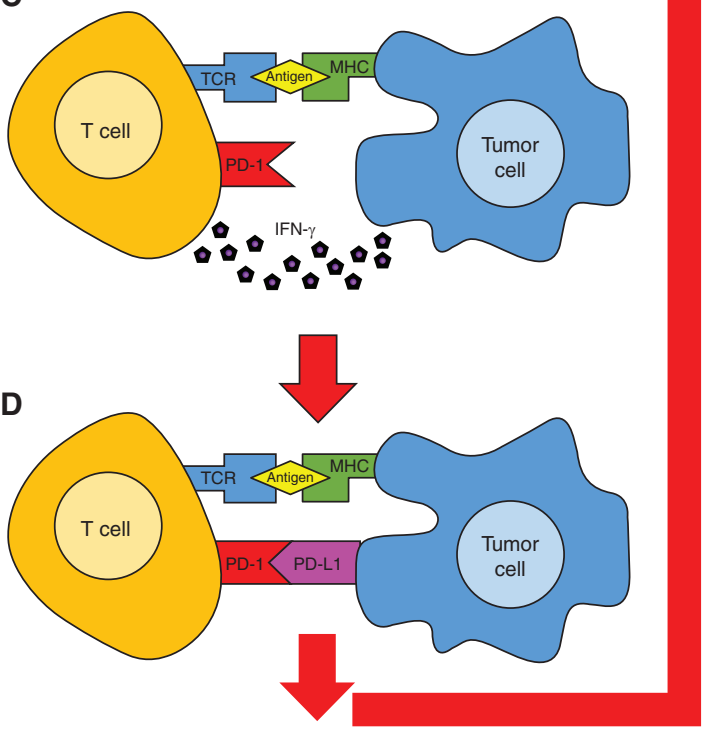

E

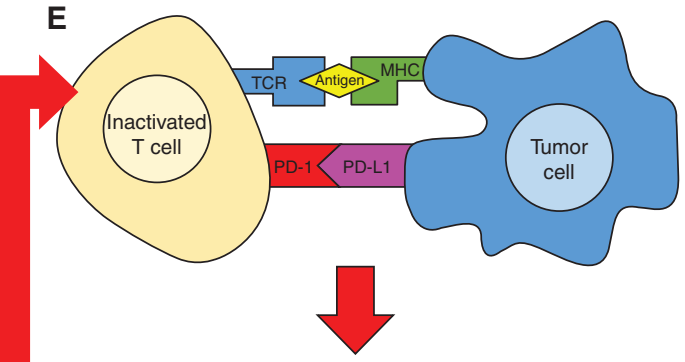

$\mathbf{F}$

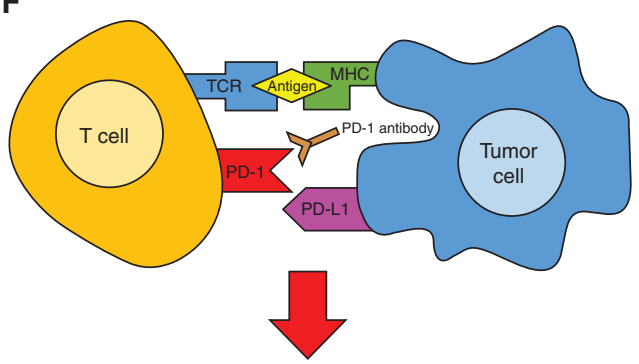

G
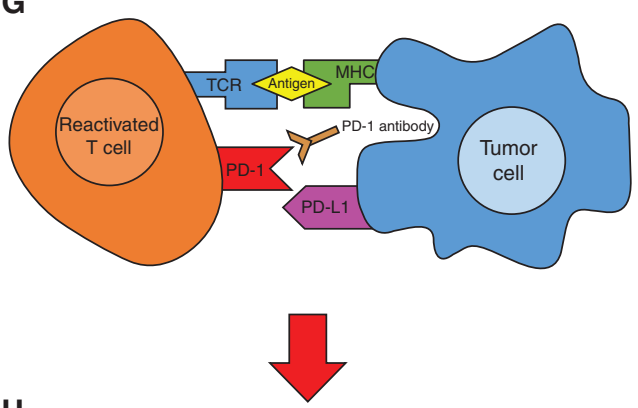

H

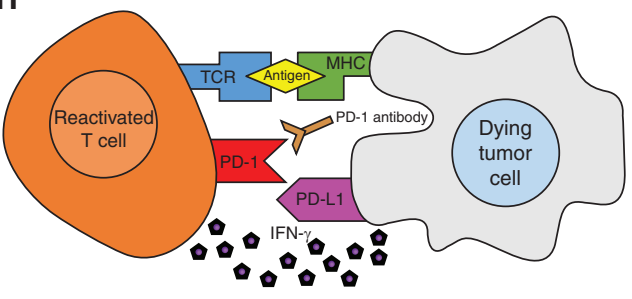

Figure 1. Adaptive immune resistance and reinvigoration of antitumor immunity by programmed death-1 (PD1) blockade. $(A-H)$ PD-1 is up-regulated by antigen recognition, leading to secretion of the effector cytokine interferon (IFN)- $\gamma$. Sensing of IFN- $\gamma$ by tumor cells results in up-regulation of PD-L1, which binds to PD- 1 on the effector T cell, strongly inhibiting T-cell effector function and adaptive immunity. PD-1 blockade inhibits this negative interaction, leading to reacquisition of T-cell effector function and tumor lysis. 
N.J. Venturini and C.G. Drake

sion of the surface of the naive $\mathrm{T}$ cell and production of IFN- $\gamma$ (Fig. 1B,C). IFN- $\gamma$ signals to the tumor cell that it is facing an imminent immune response, driving up-regulation of PD-L1 expression on the tumor cell surface (Fig. 1D). When PD-1 on the activated $\mathrm{T}$ cell binds to $\mathrm{PD}-\mathrm{L} 1$ on the tumor cell, the T cell is inactivated and the immune response is down-regulated (Fig. 1E). Antibodies that block the interaction between PD-1 and PD-L1 are active in multiple tumor types; by disrupting the PD-1/PD-L1 pathway, these antibodies restore T-cell function and antitumor activity (Fig. 1F), resulting in an immune response against the tumor (Fig. 1G), with subsequent tumor lysis (Fig. 1H). However, the success of these drugs is largely dependent on the level of PD-L1 expression in the tumor being treated, so tumors that do not express PD-L1 are generally not treatable by PD-1 blockade, at least as a monotherapy (Dallos and Drake 2018).

\section{PD-L1 EXPRESSION AND PD-1 BLOCKADE IN PROSTATE CANCER}

A recent immunohistochemistry (IHC) study of PD-L1 expression in prostate cancer showed that $7.7 \%$ of primary tumors and $32.1 \%$ of metastatic castration-resistant tumors express PD-L1 (Haffner et al. 2018). Figure 2A shows the lack of $\mathrm{PD}-\mathrm{L} 1$ expression in a primary prostate cancer lesion, and Figure $2 \mathrm{~B}$ shows the expression of PD-L1 in a metastatic prostate cancer lesion. This particular lesion, like 30\% of mCRPC lesions, shows high expression of $\mathrm{PD}-\mathrm{L} 1$. The reasonable prevalence of $\mathrm{PD}-\mathrm{L} 1$ in metastatic lesions implies that PD-1/PD-L1 blockade therapy might have a role in prostate cancer.

In that regard, a recent phase II study analyzed the activity of pembrolizumab, a PD-1 blocking antibody, in patients with docetaxelrefractory mCRPC (Bono et al. 2018). This study was the first to test the activity of anti-PD-1 monotherapy in mCRPC in a large-scale clinical trial. Eligible patients were enrolled into three cohorts: Cohort 1 included patients with RECIST-measurable tumors positive for PD-L1, cohort 2 included patients with RECIST-mea-
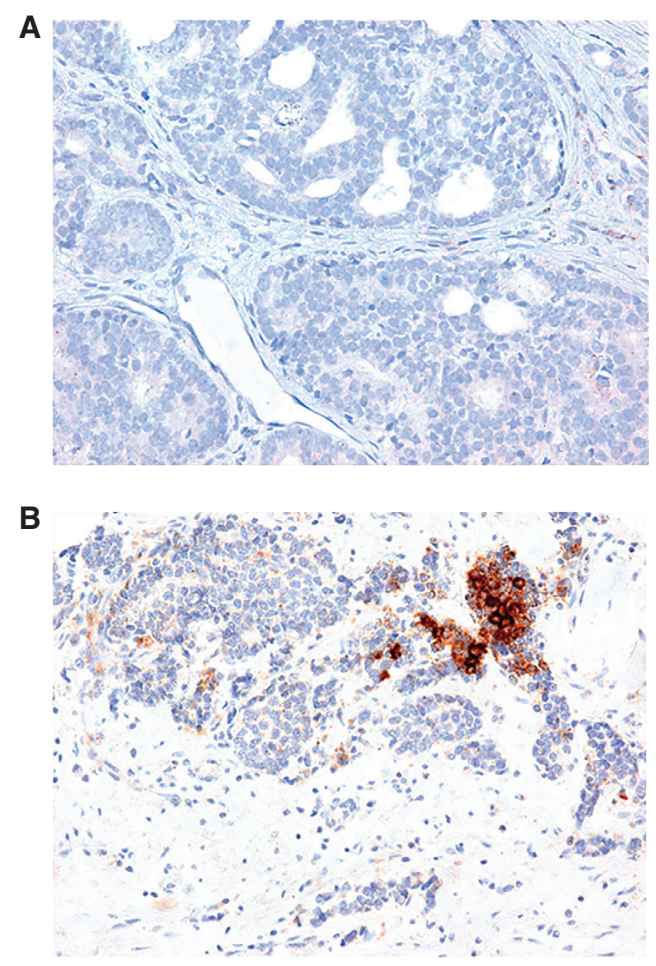

Figure 2. Ligand for programmed death-1 (PD-L1) expression in metastatic prostate cancer. $(A, B) \mathrm{Immu}-$ nohistochemistry for PD-L1 in metastatic prostate cancer lesions. The majority of stained lesions are completely PD-L1-negative $(A) ; \sim 30 \%$ stain positive for PD-L1. (Images courtesy of M. Haffner, Johns Hopkins University.)

surable tumors negative for PD-L1, and cohort 3 included patients with RECIST-nonmeasurable tumors. Anti-PD-1 monotherapy resulted in relatively modest antitumor activity in all three cohorts, with a RECIST response rate of 3\%-5\% in patients with measurable disease. In contrast, in kidney cancer the RECIST response rate to pembrolizumab monotherapy is $\sim 40 \%$ (McDermott et al. 2018) and in bladder cancer it is 25\% (Bellmunt et al. 2017). Thus, although anti-PD-1 monotherapy has some activity in MCRPC, that activity is clearly less significant than that observed in other tumor types. One exception may be the population of patients with defects in homologous DNA repair genes, as these patients showed an objective response rate of $\sim 12 \%$, with a handful of long-term responses. 


\section{COMBINING ANTI-PD-1 WITH ANDROGEN DEPRIVATION THERAPY}

Surgical or chemical castration results in apoptosis of prostate cancer epithelial cells, objective tumor regression, and drops in PSA. Thus, androgen deprivation therapy (ADT) is a mainstay of the treatment paradigm for advanced prostate cancer (Denmeade and Isaacs 2002). Thus, as long as a prostate tumor remains dependent on and sensitive to androgen levels, ADT monotherapy can be an effective treatment. Eventually, most patients with metastatic prostate cancer develop disease that progresses in the presence of castrate levels of testosteronethis is called castration-resistant prostate cancer and is where the majority of clinical agents have been developed (Scher et al. 2016). There are multiple mechanisms that underlay the development of castration resistance: They include amplification of the androgen receptor (AR), mutations in the AR, and a process by which prostate cancer cells begin to synthesize their own androgens, which induce an autocrine growth loop.

Early studies by Kwon and colleagues (Mercader et al. 2001) showed that ADT results in a pro-inflammatory infiltrate in primary prostate cancer, an effect that is mirrored in animal models. Significantly, ADT temporarily abrogates immune tolerance to the gland (Drake et al. 2005), suggesting that the combination of $\mathrm{ADT}$ and immunotherapy could prove additive or perhaps even synergistic. A recent phase II clinical trial tested that combination clinically, adding anti-PD-1 (pembrolizumab) to patients progressing on the second-generation antiandrogen enzalutamide. Early published results from that study showed that ten of the patients enrolled experienced significant reductions in circulating PSA (Graff et al. 2016). A more extended follow-up study (Graff et al. 2018) showed that $18 \%$ of participants experienced a reduction in PSA levels ( $>50 \%)$ and $25 \%$ of participants experienced a measurable radiographic response. These results are especially intriguing in light of the relatively low response rate $(3 \%$ $5 \%$ ) documented in anti-PD-1 monotherapy in the larger phase II study discussed above, and suggest that the combination of anti-PD-1 plus anti-androgens might be worthy of additional study. Indeed, a randomized phase III trial is testing that hypothesis directly, treating patients progressing on the next-generation androgen synthesis inhibitor abiraterone acetate with either enzalutamide monotherapy or the combination of enzalutamide and the anti-PD-1 antibody atezolizumab.

\section{COMBINING ANTI-PD-1/PD-L1 WITH ANTI-CTLA-4}

Cytotoxic T-lymphocyte-associated protein 4 (CTLA-4) is a critical immune checkpoint molecule, as knockout mice typically succumb to broad-based autoimmunity before 4 weeks of age (Tivol et al. 1995). CTLA-4 is closely related to CD-28, a T-cell coreceptor required for optimal T-cell activation. These two proteins are both expressed on $\mathrm{T}$ cells and both bind to the same two ligands, CD80 and CD86, although CTLA-4 has higher affinity. CTLA-4 and CD28 have opposing effects on T-cell activation; CTLA-4 inhibits activation, whereas CD-28 stimulates activation (Wolchok et al. 2013). Because tumor cells are capable of initiating immunosuppression through the CTLA-4 pathway, anti-CTLA- 4 antibodies can be used to block the binding of CTLA-4 to either CD80 or CD86 and elicit an antitumor immune response (Leach et al. 1996).

Two phase III clinical trials tested the efficacy of anti-CTLA-4 monotherapy in patients with mCRPC. One of these trials enrolled 799 patients with chemotherapy-resistant $\mathrm{MCRPC}$ who were assigned to treatment with either ipilimumab, an anti-CTLA-4 antibody, and a low dose of radiation therapy (RT) or RT plus a placebo. The study failed to meet its overall survival primary endpoint, with a nonsignificant median overall survival of 11.2 months in the ipilimumab group as compared with 10 months in the group treated with placebo (Kwon et al. 2014). A second trial enrolled 602 prechemotherapy patients who were treated with either ipilimumab or placebo; this trial differed from the first in that no radiation therapy was administered and the prechemotherapy criterion se- 
lected earlier-stage patients. The median overall survival of patients receiving ipilimumab was 28.7 months, compared with 29.7 months for patients receiving placebo (Beer et al. 2017). However, patients receiving ipilimumab had an increased median progression-free survival (5.6 months compared with 3.8 months) and a higher rate of PSA response $(23 \%$ compared with $8 \%$ ). Taken together, these two phase III trials showed that anti-CTLA-4 monotherapy has a modicum of antitumor activity in prostate cancer, and that monotherapy is unlikely to be of sufficient clinical impact for registration purposes.

CTLA-4 is highly expressed on $\mathrm{CD}^{+}{ }^{+}$regulatory T cells (Treg) in the tumor microenvironment (Simpson et al. 2013), whereas the activity of anti-PD-1 is likely restricted to CD8 (killer) T cells, as described above. In animal models, concordant blockade of both PD-1 and CTLA-4 has additive activity (Curran et al. 2010), driving enthusiasm for the combination in the clinic. Based on positive phase III data, the combination of anti-PD-1 and anti-CTLA-4 is agency approved in melanoma and kidney cancer (Motzer et al. 2018). A recent trial tested that combination in metastatic castration-resistant prostate cancer; here, the population was selected for expression of a splice variant in the androgen receptor (AR-V7) that confers resistance to hormonal therapy-AR-V7+ patients have a relatively abbreviated lifespan and high-risk disease (Antonarakis et al. 2014). This phase II trial enrolled 15 patients with tumors that expressed AR-V7. These patients were treated with ipilimumab plus nivolumab combination therapy and assessed for PSA response rate, objective response, PSA progression-free survival, clini$\mathrm{cal} /$ radiographic progression-free survival, and overall survival. Several patients had objective responses, similar to the pembrolizumab monotherapy trial discussed above. Patients with homologous DNA repair defects were the only ones to show detectable PSA responses (Boudadi et al. 2018). In keeping with prior data in other diseases, the rate of immune-related adverse events was $\sim 40 \%$, requiring the administration of immunosuppressive corticosteroids in the majority of treated patients.

\section{COMBINING ANTI-PD-1/PD-L1 WITH VACCINES}

Vaccines, like the poxvirus-based vaccines tested extensively in prostate cancer (Arlen et al. 2007), are capable of raising specific immunity in two distinct ways: direct presentation and cross-presentation. In direct presentation, the virus directly infects antigen presenting cells (APCs); the virally encoded protein encoded is then synthesized and presented in the context of class I MHC on those infected cells. In crosspresentation, the virus infects another cell type, typically an epithelial cell, resulting in lysis and uptake of cellular debris by a nearby professional APC (Fig. 3). In other words, in cross-presentation, the synthesized protein is pinocytosed by a dendritic cell and presented on MHC. Both of these pathways have the same end result: induced immunity against the encoded protein.

A recent phase III clinical trial tested the efficacy of PROSTVAC-V/F, a poxvirus-based vaccine intended to elicit an immune response against PSA, in men with minimally symptomatic mCRPC. This phase III trial was conducted after a phase II trial showed that PROSTVACV/F increased overall survival by 8.5 months (Kantoff et al. 2010). Unfortunately, this large randomized phase III study, which enrolled 1297 patients across 15 countries, failed to confirm the increase in overall survival, with a hazard ratio for overall survival of 1.02 (Gulley et al. 2018). Several other vaccine constructs are in various states of testing for prostate cancer. One vector incorporates the target antigen into an attenuated bacterial vector, listeria monocytogenes. A recent phase II trial tested the activity of ADXS-PSA, the aforementioned listeriabased vaccine also intended to elicit an immune response against PSA, with pembrolizumab. This study, which enrolled 51 patients in two groups, showed that approximately one-third of the patients treated with both ADXS-PSA and pembrolizumab experienced disease stabilization; there was also an improvement in PSA progression-free survival as compared with vaccine alone (Stein et al. 2018). Those results compare favorably with the pembrolizumab (anti-PD-1) monotherapy data, adding further 


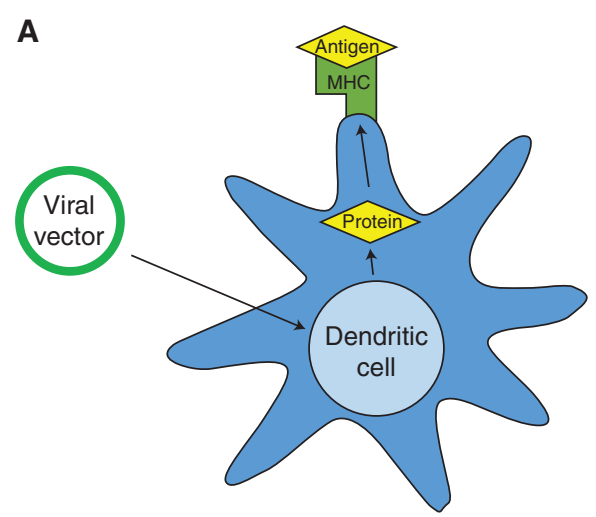

B

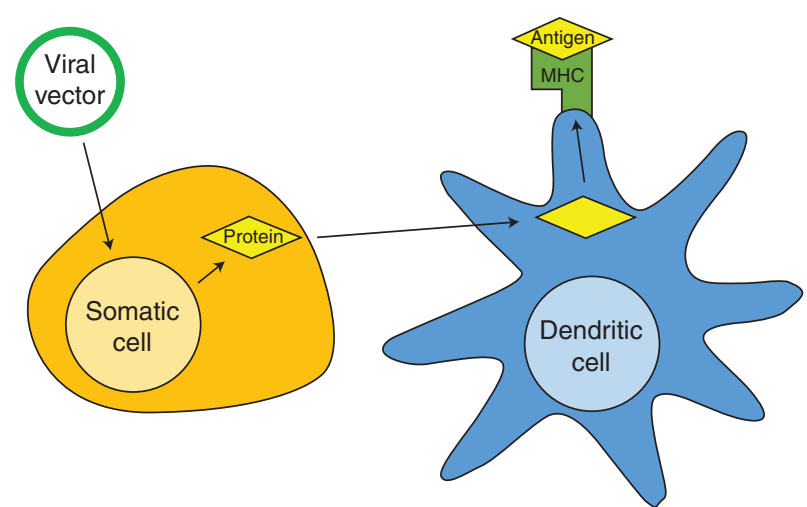

Figure 3. Direct and cross-presentation of vaccine-encoded antigens. (A) Direct presentation. The vector directly infects antigen-presenting cell, leading to processing and presentation of tumor antigen on class I major histocompatibility complex (MHC). (B) Cross-presentation. The vector infects epithelial cells, leading to lysis. Cellular debris is taken up by nearby antigen presenting cells, processed, and presented on class I MHC.

support to the notion that combination regimens may be required for immunotherapy to be active in prostate cancer.

\section{COMBINING ANTI-PD-1/PD-L1 THERAPY WITH PARP INHIBITORS}

DNA damage occurs frequently during cell division, yet cells have a host of mechanisms to ensure that DNA damage is repaired before DNA replication is allowed to conclude. Under normal circumstances, cells with unresolvable DNA damage cease proliferation and undergo apoptosis (Castro et al. 2016). Cancer cells with mutations in DNA damage repair mechanisms may rely heavily on poly(ADP-ribose) polymerase (PARP) for DNA repair to successfully proliferate. Thus, PARP inhibitors increase chromosomal instability and limit cell reproduction in affected tumor cells. Although PARP inhibitors might be expected to suppress the immune system by inhibiting proliferation of immune cells, they have actually been found to enhance antitumor immunity (Brown et al. 2018). This raises the possibility of combining PARP inhibitors with immunotherapy, such as anti-PD-1/PD-L1 therapy.

A recent phase II study assessed the activity of combining olaparib, a PARP inhibitor, with the anti-PD-L1 antibody durvalumab in men with mCRPC (Karzai et al. 2018). This study enrolled 25 patients with MCRPC; preliminary data on 17 of the patients showed that eight patients (47\%) experienced a reduction in PSA levels higher than $50 \%$, six of those patients had mutations in DNA damage repair genes. These 
early data highlight the activity of combined PARP inhibition and anti-PD-L1/PD-1 therapy, particularly in men with mutations in DNA damage repair genes.

\section{IMMUNOGENIC CELL DEATH}

Cell death can take many forms, some of which are immunologically silent and some of which instigate immune recognition. On a basic level, there are two main types of cell death: apoptosis and necrosis. Apoptosis is "programmed cell death," because it is an organized process initiated by cells themselves and is an integral part of growth and development. Apoptosis is generally immunologically silent because its end products are membrane-bound apoptotic bodies, which are quietly engulfed by nearby cells, including nonprofessional phagocytes (Sauter et al. 2000). Necrosis, on the other hand, is initiated by damage from an external modality. Necrosis is, in general, immunogenic because its end products are free cellular contents and infectious agents, which are released after cell lysis of damaged or diseased cells.

In immunogenic cell death, internal cellular contents are released, taken up by antigen presenting cells, and presented to the adaptive immune system for recognition (Zitvogel et al. 2008). This process begins when a cell dies and releases its cellular contents into the extracellular space. Through the process of macropinocytosis, dendritic cells are capable of taking up these contents; on stimulation by a pathogen-associated molecular pattern (PAMP) (Medzhitov and Janeway 2000), dendritic cells cease antigen uptake and begin processing the antigen so that it may be presented on the surface of the dendritic cell in conjunction with MHC class I. At this point, the dendritic cell migrates to the lymphatic system to interact with and activate the $\mathrm{CD} 8^{+} \mathrm{T}$ lymphocytes of the adaptive immune system.

Understanding and manipulating this process may be critical for cancer immunotherapy to be successful. Because radiation therapy results in direct cellular damage and inflammation, it is generally immunogenic (Sharabi et al. 2015). Likewise, some chemotherapy agents, but not all, result in immunogenic cell death. Tax- anes, the only class of chemotherapy drugs used currently to treat prostate cancer, have immunogenic properties (Pfannenstiel et al. 2010). These chemotherapy drugs can be used to prime the immune system, as has been shown in works in lung cancer, so combining immunotherapy and chemotherapy may be a particularly effective way to coordinate immunogenic cell death and immune system activation. Several phase II trials in prostate cancer include combinations of anti-PD-1/PD-L1 therapy plus chemotherapy. However, enthusiasm for those results is tempered by the notion that docetaxel-based combination phase III studies have uniformly been negative, often despite promising phase II data (Antonarakis and Eisenberger 2013).

\section{CONCLUSIONS}

Despite the widespread enthusiasm for immunotherapy, not all tumor types appear to be immune-sensitive. These so-called "cold" tumors include some of the more common causes of cancer death, as both breast cancer and prostate cancer are relatively insensitive to immunotherapy with PD-1/PD-L1 blockade or with CTLA-4 blockade. The mechanisms underlying this lack of immune responsiveness in prostate cancer are currently unknown. One possibility is a lack of a sufficient number of mutations to drive antitumor immunity. In general, more heavily mutated tumors, like non-small cell lung cancer (especially when caused by smoking) and bladder cancer, appear to be more sensitive, although exceptions like clear cell kidney cancer with 40 to 70 mutations per tumor and a good (20\%) response rate to anti-PD-1 muddy the waters to some degree. A second mechanism for this lack of response might be the presence of suppressive cell populations in the prostate tumor microenvironment, including regulatory $\mathrm{T}$ cells discussed above as well as a population of myeloid-derived suppressor cells (MDSCs) (Lopez-Bujanda and Drake 2017), which have thus far not been successfully targeted. One solution to this lack of responsiveness to monotherapy is combination therapy, but optimal combinations for prostate cancer are challenging to compose without additional data regarding the 
cellular composition and characteristics of the prostate tumor microenvironment. On a more positive note, patients with acquired or germline homologous recombination deficiencies seem to have a better chance of responding to anti-PD-1/ PD-L1 therapy, either alone or in combination. Because $\sim 20 \%-25 \%$ of patients with advanced prostate cancer have these mutations (Robinson et al. 2015), this represents a fairly sizable target population. Going forward, it remains to be seen whether immunotherapy will become a mainstay of prostate cancer therapy.

\section{REFERENCES}

Agata Y, Kawasaki A, Nishimura H, Ishida Y, Tsubata T, Yagita H, Honjo T. 1996. Expression of the PD-1 antigen on the surface of stimulated mouse $\mathrm{T}$ and $\mathrm{B}$ lymphocytes. Int Immunol 8: 765-772.

Antonarakis ES, Eisenberger MA. 2013. Phase III trials with docetaxel-based combinations for metastatic castrationresistant prostate cancer: Time to learn from past experiences. J Clin Oncol 31: 1709-1712.

Antonarakis ES, Lu C, Wang H, Luber B, Nakazawa M, Roeser JC, Chen Y, Mohammad TA, Chen Y, Fedor HL, et al. 2014. AR-V7 and resistance to enzalutamide and abiraterone in prostate cancer. N Engl J Med 371: 10281038.

Arlen PM, Gulley JL, Madan RA, Hodge JW, Schlom J. 2007. Preclinical and clinical studies of recombinant poxvirus vaccines for carcinoma therapy. Crit Rev Immunol 27: 451-462.

Beer TM, Kwon ED, Drake CG, Fizazi K, Logothetis C, Gravis G, Ganju V, Polikoff J, Saad F, Humanski P, et al. 2017. Randomized, double-blind, phase III trial of ipilimumab versus placebo in asymptomatic or minimally symptomatic patients with metastatic chemotherapy-naive castration-resistant prostate cancer. J Clin Oncol 35: 40-47.

Bellmunt J, de Wit R, Vaughn DJ, Fradet Y, Lee JL, Fong L, Vogelzang NJ, Climent MA, Petrylak DP, Choueiri TK, et al. 2017. Pembrolizumab as second-line therapy for advanced urothelial carcinoma. N Engl J Med 376: 1015-1026.

Bono JSD, Goh JC, Ojamaa K, Rodriguez JMP, Drake CG Hoimes CJ, Wu H, Poehlein CH, Antonarakis ES. 2018. KEYNOTE-199: Pembrolizumab (pembro) for docetaxel-refractory metastatic castration-resistant prostate cancer (mCRPC). J Clin Oncol 36: 5007-5007.

Boudadi K, Suzman DL, Anagnostou V, Fu W, Luber B, Wang H, Niknafs N, White JR, Silberstein JL, Sullivan $\mathrm{R}$, et al. 2018. Ipilimumab plus nivolumab and DNArepair defects in AR-V7-expressing metastatic prostate cancer. Oncotarget 9: 28561-28571.

Brown JS, Sundar R, Lopez J. 2018. Combining DNA damaging therapeutics with immunotherapy: More haste, less speed. Br J Cancer 118: 312-324.

Castro E, Mateo J, Olmos D, de Bono JS. 2016. Targeting DNA repair: The role of PARP inhibition in the treatment of castration-resistant prostate cancer. Cancer J 22: 353 356.

Curran MA, Montalvo W, Yagita H, Allison JP. 2010. PD-1 and CTLA- 4 combination blockade expands infiltrating T cells and reduces regulatory $\mathrm{T}$ and myeloid cells within $\mathrm{B} 16$ melanoma tumors. Proc Natl Acad Sci 107: 4275-4280.

Dallos MC, Drake CG. 2018. Blocking PD-1/PD-L1 in genitourinary malignancies: To immunity and beyond. Cancer J 24: 20-30.

Denmeade SR, Isaacs JT. 2002. A history of prostate cancer treatment. Nat Rev Cancer 2: 389-396.

Dong H, Zhu G, Tamada K, Chen L. 1999. B7-H1, a third member of the B7 family, co-stimulates T-cell proliferation and interleukin-10 secretion. Nat Med 5: 1365-1369.

Drake CG, Doody AD, Mihalyo MA, Huang CT, Kelleher E, Ravi S, Hipkiss EL, Flies DB, Kennedy EP, Long M, et al. 2005. Androgen ablation mitigates tolerance to a prostate/ prostate cancer-restricted antigen. Cancer Cell 7: 239-249.

Drake CG, Lipson EJ, Brahmer JR. 2014. Breathing new life into immunotherapy: Review of melanoma, lung and kidney cancer. Nat Rev Clin Oncol 11: 24-37.

Dunn GP, Old LJ, Schreiber RD. 2004. The immunobiology of cancer immunosurveillance and immunoediting. Immunity 21: 137-148.

Graff JN, Alumkal JJ, Drake CG, Thomas GV, Redmond WL, Farhad M, Cetnar JP, Ey FS, Bergan RC, Slottke R, et al. 2016. Early evidence of anti-PD-1 activity in enzalutamide-resistant prostate cancer. Oncotarget 7: 5281052817.

Graff JN, Alumkal JJ, Thompson RF, Moran A, Thomas GV, Wood MA, Drake CG, Slottke R, Beer TM. 2018. Pembrolizumab (Pembro) plus enzalutamide (Enz) in metastatic castration resistant prostate cancer (mCRPC): Extended follow up. J Clin Oncol 36: 5047-5047.

Gulley JL, Borre M, Vogelzang NJ, Ng S, Agarwal N, Parker CC, Pook DW, Rathenborg P, Flaig TW, Carles J, et al. 2018. Results of PROSPECT: A randomized phase 3 trial of PROSTVAC-V/F (PRO) in men with asymptomatic or minimally symptomatic metastatic, castration-resistant prostate cancer. J Clin Oncol 36: 5006-5006.

Haffner MC, Guner G, Taheri D, Netto GJ, Palsgrove DN, Zheng Q, Guedes LB, Kim K, Tsai H, Esopi DM, et al. 2018. Comprehensive evaluation of programmed deathligand 1 expression in primary and metastatic prostate cancer. Am J Pathol 188: 1478-1485.

Ishida Y, Agata Y, Shibahara K, Honjo T. 1992. Induced expression of PD-1, a novel member of the immunoglobulin gene superfamily, upon programmed cell death. EMBO J 11: 3887-3895.

Kantoff PW, Schuetz TJ, Blumenstein BA, Glode LM, Bilhartz DL, Wyand M, Manson K, Panicali DL, Laus R, Schlom J, et al. 2010. Overall survival analysis of a phase II randomized controlled trial of a poxviral-based PSAtargeted immunotherapy in metastatic castration-resistant prostate cancer. J Clin Oncol 28: 1099-1105.

Karzai F, Madan RA, Owens H, Couvillon A, Hankin A, Williams M, Bilusic M, Cordes LM, Trepel JB, Killian $\mathrm{K}$, et al. 2018. A phase 2 study of olaparib and durvalumab in metastatic castrate-resistant prostate cancer (mCRPC) in an unselected population. J Clin Oncol (Suppl) 36: 163-163. 
Keir ME, Liang SC, Guleria I, Latchman YE, Qipo A, Albacker LA, Koulmanda M, Freeman GJ, Sayegh MH, Sharpe AH. 2006. Tissue expression of PD-L1 mediates peripheral T cell tolerance. J Exp Med 203: 883-895.

Kwon ED, Drake CG, Scher HI, Fizazi K, Bossi A, van den Eertwegh AJ, Krainer M, Houede N, Santos R, Mahammedi $\mathrm{H}$, et al. 2014. Ipilimumab versus placebo after radiotherapy in patients with metastatic castration-resistant prostate cancer that had progressed after docetaxel chemotherapy (CA184-043): A multicentre, randomised, double-blind, phase 3 trial. Lancet Oncol 15: 700-712.

LaFleur MW, Muroyama Y, Drake CG, Sharpe AH. 2018. Inhibitors of the PD-1 pathway in tumor therapy. J Immunol 200: 375-383.

Leach DR, Krummel MF, Allison JP. 1996. Enhancement of antitumor immunity by CTLA-4 blockade. Science 271: 1734-1736.

Lopez-Bujanda Z, Drake CG. 2017. Myeloid-derived cells in prostate cancer progression: Phenotype and prospective therapies. J Leukoc Biol 102: 393-406.

Martin AM, Nirschl TR, Nirschl CJ, Francica BJ, Kochel CM van Bokhoven A, Meeker AK, Lucia MS, Anders RA, DeMarzo AM, et al. 2015. Paucity of PD-L1 expression in prostate cancer: Innate and adaptive immune resistance. Prostate Cancer Prostatic Dis 18: 325-332.

McDermott DF, Lee JL, Szczylik C, Donskov F, Malik J, Alekseev BY, Larkin JMG, Matveev VB, Gafanov RA, Tomczak P, et al. 2018. Pembrolizumab monotherapy as first-line therapy in advanced clear cell renal cell carcinoma (accRCC): Results from cohort A of KEYNOTE-427. J Clin Oncol 36: 4500-4500.

Medzhitov R, Janeway C Jr. 2000. Innate immune recognition: Mechanisms and pathways. Immunol Rev 173: 89-97.

Mercader M, Bodner BK, Moser MT, Kwon PS, Park ES, Manecke RG, Ellis TM, Wojcik EM, Yang D, Flanigan RC, et al. 2001. T cell infiltration of the prostate induced by androgen withdrawal in patients with prostate cancer. Proc Natl Acad Sci 98: 14565-14570.

Motzer RJ, Tannir NM, McDermott DF, Aren Frontera O, Melichar B, Choueiri TK, Plimack ER, Barthelemy P, Porta C, George S, et al. 2018. Nivolumab plus ipilimumab versus sunitinib in advanced renal-cell carcinoma N Engl J Med 378: 1277-1290

Nishimura H, Agata Y, Kawasaki A, Sato M, Imamura S, Minato N, Yagita H, Nakano T, Honjo T. 1996. Developmentally regulated expression of the $\mathrm{PD}-1$ protein on the surface of double-negative $\left(\mathrm{CD} 4^{-} \mathrm{CD} 8^{-}\right)$thymocytes. Int Immunol 8: 773-780.

Nishimura H, Okazaki T, Tanaka Y, Nakatani K, Hara M, Matsumori A, Sasayama S, Mizoguchi A, Hiai H, Minato $\mathrm{N}$, et al. 2001. Autoimmune dilated cardiomyopathy in PD-1 receptor-deficient mice. Science 291: 319-322.

Paller CJ, Antonarakis ES, Eisenberger MA, Carducci MA. 2013. Management of patients with biochemical recurrence after local therapy for prostate cancer. Hematol Oncol Clin North Am 27: 1205-1219.

Pfannenstiel LW, Lam SS, Emens LA, Jaffee EM, Armstrong TD. 2010. Paclitaxel enhances early dendritic cell maturation and function through TLR4 signaling in mice. Cell Immunol 263: 79-87.

Robinson D, Van Allen EM, Wu YM, Schultz N, Lonigro RJ, Mosquera JM, Montgomery B, Taplin ME, Pritchard CC,
Attard G, et al. 2015. Integrative clinical genomics of advanced prostate cancer. Cell 161: 1215-1228.

Sanda MG, Cadeddu JA, Kirkby E, Chen RC, Crispino T, Fontanarosa J, Freedland SJ, Greene K, Klotz LH, Makarov DV, et al. 2018. Clinically localized prostate cancer: AUA/ASTRO/SUO Guideline. Part II: Recommended approaches and details of specific care options. J Urol 199: 990-997.

Sauter B, Albert ML, Francisco L, Larsson M, Somersan S, Bhardwaj N. 2000. Consequences of cell death: Exposure to necrotic tumor cells, but not primary tissue cells or apoptotic cells, induces the maturation of immunostimulatory dendritic cells. J Exp Med 191: 423-434.

Scher HI, Morris MJ, Stadler WM, Higano C, Basch E, Fizazi $\mathrm{K}$, Antonarakis ES, Beer TM, Carducci MA, Chi KN, et al. 2016. Trial design and objectives for castration-resistant prostate cancer: Updated recommendations from the prostate cancer clinical trials working group 3. J Clin Oncol 34: 1402-1418.

Sharabi AB, Lim M, DeWeese TL, Drake CG. 2015. Radiation and checkpoint blockade immunotherapy: Radiosensitisation and potential mechanisms of synergy. Lancet Oncol 16: e498-e509.

Siegel RL, Miller KD, Jemal A. 2018. Cancer statistics, 2018. CA Cancer J Clin 68: 7-30.

Simpson TR, Li F, Montalvo-Ortiz W, Sepulveda MA, Bergerhoff K, Arce F, Roddie C, Henry JY, Yagita H, Wolchok JD, et al. 2013. Fc-dependent depletion of tumor-infiltrating regulatory $T$ cells co-defines the efficacy of anti-CTLA4 therapy against melanoma. J Exp Med 210: 1695-1710.

Stein MN, Fong L, Tutrone RF, Mega AE, Lobo M, Hong Q, Haas NB. 2018. KEYNOTE-046: ADXS-PSA plus pembrolizumab (pembro) in metastatic castration-resistant prostate cancer (mCRPC). J Clin Oncol 36: 5019-5019.

Taube JM, Anders RA, Young GD, Xu H, Sharma R, McMiller TL, Chen S, Klein AP, Pardoll DM, Topalian SL, et al. 2012. Colocalization of inflammatory response with b7h1 expression in human melanocytic lesions supports an adaptive resistance mechanism of immune escape. Sci Transl Med 4: 127ra137.

Tivol EA, Borriello F, Schweitzer AN, Lynch WP, Bluestone JA, Sharpe AH. 1995. Loss of CTLA-4 leads to massive lymphoproliferation and fatal multiorgan tissue destruction, revealing a critical negative regulatory role of CTLA4. Immunity 3: 541-547.

Topalian SL, Hodi FS, Brahmer JR, Gettinger SN, Smith DC McDermott DF, Powderly JD, Carvajal RD, Sosman JA, Atkins MB, et al. 2012. Safety, activity, and immune correlates of anti-PD-1 antibody in cancer. N Engl J Med 366: 2443-2454.

Topalian SL, Drake CG, Pardoll DM. 2015. Immune checkpoint blockade: A common denominator approach to cancer therapy. Cancer Cell 27: 450-461.

Wolchok JD, Hodi FS, Weber JS, Allison JP, Urba WJ, Robert C, O’Day SJ, Hoos A, Humphrey R, Berman DM, et al. 2013. Development of ipilimumab: A novel immunotherapeutic approach for the treatment of advanced melanoma. Ann NY Acad Sci 1291: 1-13.

Zitvogel L, Apetoh L, Ghiringhelli F, Andre F, Tesniere A, Kroemer G. 2008. The anticancer immune response: Indispensable for therapeutic success? J Clin Invest 118: 1991-2001. 


\section{$\&_{\mathrm{CSH}}^{\infty} \&$ Cold Spring Harbor

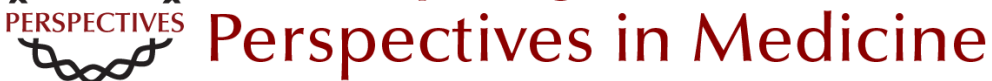

\section{Immunotherapy for Prostate Cancer}

Nicholas J. Venturini and Charles G. Drake

Cold Spring Harb Perspect Med 2019; doi: 10.1101/cshperspect.a030627 originally published online September 10, 2018

\section{Subject Collection Prostate Cancer}

Anatomic and Molecular Imaging in Prostate Cancer

Eric T. Miller, Amirali Salmasi and Robert E. Reiter

The Epidemiology of Prostate Cancer Claire H. Pernar, Ericka M. Ebot, Kathryn M. Wilson, et al.

Prostate Stem Cells and Cancer Stem Cells Jia J. Li and Michael M. Shen

Prostate Cancer Epigenetics: From Basic Mechanisms to Clinical Implications Srinivasan Yegnasubramanian, Angelo M. De Marzo and William G. Nelson

\section{The Genomics of Prostate Cancer: A Historic} Perspective Mark A. Rubin and Francesca Demichelis

Neuroendocrine Differentiation in Prostate

Cancer: Emerging Biology, Models, and Therapies Loredana Puca, Panagiotis J. Vlachostergios and Himisha Beltran

DNA Damage Response in Prostate Cancer Matthew J. Schiewer and Karen E. Knudsen

Transcriptional Regulation in Prostate Cancer David P. Labbé and Myles Brown
New Opportunities for Targeting the Androgen Receptor in Prostate Cancer Margaret M. Centenera, Luke A. Selth, Esmaeil Ebrahimie, et al.

Prostate Cancer Research at the Crossroads Michael M. Shen and Mark A. Rubin

Immunotherapy for Prostate Cancer Nicholas J. Venturini and Charles G. Drake

Molecular Pathology of High-Grade Prostatic Intraepithelial Neoplasia: Challenges and Opportunities Levent Trabzonlu, Ibrahim Kulac, Qizhi Zheng, et al.

Metastases in Prostate Cancer Federico La Manna, Sofia Karkampouna, Eugenio Zoni, et al.

Genetically Engineered Mouse Models of Prostate Cancer in the Postgenomic Era Juan M. Arriaga and Cory Abate-Shen

Molecular Biomarkers in the Clinical Management of Prostate Cancer Aaron M. Udager and Scott A. Tomlins

Metabolic Vulnerabilities of Prostate Cancer: Diagnostic and Therapeutic Opportunities Giorgia Zadra and Massimo Loda

For additional articles in this collection, see http://perspectivesinmedicine.cshlp.org/cgi/collection/ 